\title{
Information and Communication Technology to Facilitate Learning for Students in the Health Professions: Current Uses, Gaps, and Future Directions
}

\author{
Ellen Costello, Mary Corcoran, Jacqueline S. Barnett, \\ Marisa Birkmeier, Rhea Cohn, Ozgur Ekmekci, Nancy L. Falk, Thomas Harrod, \\ Debra Herrmann, Sean Robinson, Bryan Walker \\ The George Washington University \\ School of Medicine and Health Sciences \\ School of Nursing
}

\begin{abstract}
Changes in the U.S. Healthcare System along with the need for institutions of higher education to prepare a work force ready to address the challenges of today and tomorrow have highlighted the need to incorporate technology in its broadest sense as part of the student learning experience. In health professional education, this becomes challenging as programs have traditionally relied on face-to-face instruction along with internship experiences which provide hands on patient care. In addition, learning activities that incorporate higher order critical thinking must be incorporated in order to meet competency based professional expectations as well as expectations in the work place environment. This article will address current technology use in health professional education programs and identify opportunities to incorporate technology to enhance the student learning experiences with emphasis on the critical thinking, communication, and psychomotor skills required of today's health professional graduate.
\end{abstract}

\section{Introduction}

Expectations for graduating healthcare professionals (including physicians; physician assistants, dentists, nurse practioners and nurses; physical and occupational therapists; and psychologists and healthcare administrators) have evolved over the past few decades. These changes are often associated with changes in the U.S. Healthcare System and more recently as a result of the adoption of the Patient Protection and Affordable Care Act (ACA) (Gastmyer \& Pruitt, 2014). As a result of the implementation of the ACA and other change agents, today's focus in healthcare is on improving quality, efficiency and accountability. New modes of payment and care delivery in the form of "patient medical homes" and "accountable care organizations" set the stage for interprofessional delivery of care, a concept not typically practiced in a system that favors specialization. Thus, institutions of higher education have a responsibility to prepare today and tomorrow's healthcare professional to "hit the ground running" as they enter the workforce. Graduating clinicians need to be up-to-date and futuristic, while being flexible, with the ability to adapt to a changing healthcare landscape. 
These circumstances present unique challenges for educators of healthcare practitioners. Students and graduates need the requisite knowledge, skills and behaviors to practice in a complex healthcare environment. However, simulation of such a dynamic environment in an educational institution is difficult. In order for students to integrate didactic knowledge, psychomotor skills (skills that combine muscle activity and mental processing) and clinical decision-making in a real and practical way, health professional curricula require students intern at clinical training sites (e.g., hospitals, rehabilitation centers, outpatient clinics, private practices). In these settings, health professional interns are paired with licensed practitioners who oversee student progress. Unfortunately, this often results in a temporary decrease in productivity on the part of the supervising practitioner. As a result, many clinical training sites are limiting these opportunities for student training as a cost cutting measure. This ultimately shifts additional teaching and learning responsibilities back to educational programs.

Consequently educational programs must develop learning opportunities that simulate real life patient care experiences that facilitate higher order thinking as well as provide opportunities for psychomotor skill acquisition. Optimally, these experiences should all occur within a healthcare team; however a representative "team" of students may not be available at each educational institution. Additional challenges include a potential mismatch between available technology for simulation (e.g., diagnostic and interventional equipment, software) at educational institutions versus technology available at work sites. Students may be learning on equipment that is dated or different from what is encountered in the workforce. For these reasons and more, innovative use of technology in health professional education becomes essential in order to overcome some of these potential hurdles.

The focus of this article is to describe technology use in today's healthcare professional educational programs and to explore additional teaching and learning opportunities where technology could enhance the preparation of future clinicians. Audiences outside of healthcare education will be interested in how technology directly supports acquisition of the specific professional skills used in the workplace. We have identified several areas in which technology plays an important role in the educational process for healthcare professionals. These areas include patient simulation (including standardized patients), supporting interprofessional team functions, training in use of informatics (including the electronic medical record), enhancing communication through social media, and promoting information literacy. We will discuss each of these areas in this article.

\section{Information and Communication Technology to Facilitate Learning for Students in the Health Professions: Current Uses, Gaps, and Future Directions}

\section{The Increasing Use of Information and Communication Technology}

Emergent telecommunications tools are altering the nature of communication in academia and in clinical practice. As with many fields, innovations in healthcare are made possible by a vast range of technological tools including the Internet, local and wide area networks, cloud computing, Bluetooth ${ }^{\circledR}$ technology, cell phones, global positioning systems, Wi-Fi, personal digital assistants, smartphones, and tablet computers. With the emergence of Web 2.0 (the second generation of the Internet), a dynamic interconnectedness is now available through online communities, wikis, blogs, and social networking (Sandars, 2012) which potentially link consumers and providers on health-related topics. Technologies that support telehealth make it possible for patients and providers to interact from a distance when inperson meetings are not feasible (Bulik \& Shokar, 2010). How we work, communicate, and learn is changing as a result of readily accessible and reliable technology. For example, video conferencing offers the potential for assessment of student skills, at a distance, by clinical educators and mentors (Hawkins, 2012), or discussions between patient and provider who are physically separate. More than ever, educators, students, providers, consumers and other important stakeholders must gain new skills to stay current and be effective. 
To harness technological changes, it is important that educators increase their applied understanding of technology tools such as hardware, software, and applications. Effective educators must be able to capture the attention of today's students and be instrumental in helping them learn about telecommunications and other emerging technologies. By way of illustration, in a face-to-face classroom and in online learning, use of student polling facilitates active learning. Video conferencing, in use for webinars and group collaboration, fosters interaction and connectivity (Pilcher \& Bradley, 2013). Tools such as Skype ${ }^{\mathrm{TM}}$, Facetime ${ }^{\circledR}$, and real-time chatting allow healthcare professionals, in education and in practice, to connect readily and at a distance. Free or low cost technology tools such as Doodle ${ }^{\circledR}$ scheduling and FreeConference ${ }^{\circledR}$ facilitate connectivity allowing collaboration regardless of location. These tools are particularly useful when students are completing their experiential training at clinical sites which may be located in other states or even in different countries from their home campuses. The way we interact in the context of education and healthcare has changed and will continue to change. At the same time, new technologies provide exciting opportunities for faculty, students, and clinical educators to stay connected.

\section{Gaps in Preparing Healthcare Professionals}

Information and communication technology (ICT) education is an essential element in instructional programs for healthcare professionals today. By definition, ICT is "a range of technologies for gathering, storing, retrieving, processing, analyzing, transmitting and receiving information” (p. 5) (The Royal Society, 2006) . Research shows ICT education can enhance technological competence and help prepare students for the workplace (Bembridge, Levett-Jones, \& Jeong, 2011; Bulik \& Shokar, 2010; Creedon \& Cummins, 2012). Yet, gaps exist within ICT education and the use of technology in education varies within and across health professions (Bembridge et al.; Bulik \& Shokar). In some cases technological tools are not adopted by education programs because they are viewed as too costly or as inefficient (Mason, Turgeon, Cossman, \& Lay, 2014). Variation in healthcare education technology use is also driven by the fact that educators have different skill levels in the use of technology to enhance student learning through ICT education (Voogt, Knezek, Cox, Knezek, \& Brummelhuis, 2013). Additionally, students and educators have varied perceptions, attitudes, and levels of motivation regarding the acquisition of ICT understanding (Bembridge et al.; Lam, Amon, Nguyen, Campbell, \& Neville, 2012; Levett-Jones et al., 2009; Sandars, 2012), exhibiting different degrees of knowledge and applied understanding about technology, how to use devices and applications, and beliefs about the role of technology in education and in the workplace.

\section{Filling the Gaps}

The ACA underscores the importance of strengthening access to information as well as communication technology understanding and skills in order to provide cost effective care. This requires enhanced patient-provider engagement which is impacted by how healthcare providers, patients, and other key stakeholders collectively embrace and utilize tools (e.g., electronic health records, portal, handheld devises) and other emerging technologies.

To ensure that future healthcare providers acquire the requisite ICT knowledge and skills, educational institutions should provide hands-on technology-based learning opportunities. Workshops developed and delivered collaboratively and interprofessionally by information technology experts (e.g., hardware/software specialists, instructional designers) and health professionals can increase knowledge, skills, and ICT confidence among educators and students. When educators make a personal commitment to stay up-to-date on the latest tools and technologies, they are better poised to facilitate ICT education and learning. Professional organizations such as the American Telemedicine Association (ATA) and the American Medical Informatics Association (AMIA) provide learning experiences that benefit health professionals from a wide range of health disciplines. In addition, specialty journals provide information and practical applications that enhance technological understanding and confidence among today's educators and students. 
In and beyond the classroom, partnerships provide applied learning opportunities for future healthcare providers. Intel has worked collaboratively with health professions educators to transform ICT education by providing tools and guidance that facilitate learning (Intel Corporation, 2010). By incorporating technology tools into education, students gain new skills that may be directly transferable to the work environment, particularly if the content of the educational partnering opportunities map to the skills needed to function effectively within the healthcare environment. Collaborations between industry, foundations, and government have the potential to positively transform healthcare and patient care (Center for Integration of Medicine and Innovative Technology, 2014). By exchanging ideas and working together on projects that incorporate technology, health professionals gain understanding that goes well-beyond classroom learning. As an example, by making electronic health records and other such products available to students and educators at low or no cost, corporations help to prepare students for a successful employment transition.

Although ICT is here to stay, the type of technologies in use will continue to evolve. It follows that ICT education is vital in preparing a workforce that is ready to deliver high quality patient care in an increasingly complex healthcare environment. To prepare the health professionals of today and tomorrow, educators must increase their level of understanding and integrate technology into teaching and learning. In the George Washington (GW) School of Medicine and Health Sciences, we support faculty in the use of technology by locating a "technology laboratory" (equipped with hardware and software) in a central location for convenient access by students and faculty. This technology laboratory is staffed by instructional designers and multimedia specialists who provide guidance and encouragement to faculty as they try out different technologies. These services are also available to students as it is equally imperative students recognize the value of ICT education and embrace it so they not only survive, but thrive in the workplace.

\section{Patient Simulation: Multi-media Clinical Case Simulation, Clinical Reasoning, and Standardized Patients}

Clinical reasoning (CR), or diagnostic thinking, is a critical skill for health professional students to develop in order to be competent healthcare providers. Clinical reasoning as it relates to patient care is broadly defined as the decision-making process health professionals employ to manage patient care (Higgs \& Jones, 2000). One way healthcare professional education has addressed the development of clinical reasoning is through problem-based learning (PBL). Rochmawati and Wiechula (2010) have defined PBL as "the learning that results from the process of working toward the understanding or resolution of a problem, aiming to facilitate students to learn in an effective, accessible, and integrated way and to foster clinical reasoning or problem-solving skills" (p. 244). With the advent of high and low fidelity patient simulators and multi-media clinical case simulation software (MMCCSS), the PBL concept has been updated from what was once a text-based only platform (Maldonado, 2011).

The DxR Clinician ${ }^{\mathrm{TM}}$ is software developed for PBL in the 1990s by the DxR Development Group. This web-based software provides multi-media clinical case simulations for problem-based learning for medical, physician assistant, and nurse practitioner students. The software provides patient cases with various multi-media modalities including audio, photos, and videos. One of the most useful features of the DxR Clinician ${ }^{\mathrm{TM}}$ software is its ability to calculate a clinical reasoning score based on the student's choice of history questions, physical exam, test/lab selections and a differential diagnosis. Although the validity of these automated clinical reasoning scores is still under review (Jerant \& Azari, 2004), educators can use the scores to track student progress in developing this competency. The DxR Development Group has also created similar programs for physical therapy and nursing students as well. Recently, a self-efficacy survey was administered to two cohorts of GW physical therapy students prior to their first clinical training internship. One cohort of students engaged in a series of four hospital-based computer assisted learning (CAL) modules similar to the DxR Clinician ${ }^{\mathrm{TM}}$ while the other cohort did not. Preliminary results reveal a significant difference in student self-efficacy regarding preparation for practice in a hospital based environment. Students who used the CAL modules were more confident in 
their abilities to practice safely and effectively in the hospital based environment as compared to students who did not $(\mathrm{p}<.0001)$.

Educational programs are also utilizing patient simulation in an effort to mimic real life patient encounters. Sanford (2010) describes the advantages of simulation as the "ability to experience a crisis situation before it occurs in the clinical setting; the ability to evaluate and reflect on the activities in a non-threatening arena; and the predictability of being able to artificially create situations which may never occur in any other way" (p. 1010). Simulation has been used to address the lack of clinical training sites and experiences for certain types of patient encounters and to supplement training where depth and breadth may be lacking. Simulation can take on the form of a high fidelity electronically programmed mannequin or a standardized patient encounter in which an actor portrays certain signs or symptoms and adheres to a prescribed script. Literature regarding student outcomes using high fidelity simulation is limited, and much of the research has focused on student opinion without the rigor necessary to support its use. However, more recently Watson and colleagues (2012) conducted a two-group, single-blind, multi-centered randomized clinical trial (RCT) comparing simulated learning environments (SLE) to traditional clinical training. The authors reported that $25 \%$ of clinical time with real patients can be replaced with SLE without compromising student learning outcomes, in this case, student competency on clinical examinations. This study adds to the literature supporting the use of simulation as a training tool that may substitute for part of the required contact hours in direct patient care. However the complexities of personal communication and interaction between a healthcare provider and a patient cannot be realistically simulated using high fidelity mannequins and does not replace the face-to-face interaction required to develop empathy and patient-practitioner rapport.

\section{Standardized Patients}

Communication skills in healthcare should be treated and taught as any other psychomotor or procedural skill and competency should be demonstrated during the student's training (Henry, Holmboe, \& Frankel, 2013). At the GW Physician Assistant Program, technology has been used to assess a student's oral communication skills when interacting with standardized patients giving the student the opportunity to develop communication skills in a safe environment. A student will engage in a standardized patient encounter for a focused and common medical complaint, which is video and audio recorded. The student then delivers an oral case presentation (OCP)—also videotaped — which details the historical and physical exam data obtained as well as a formulated differential diagnosis and plan. The OCP is assessed by a faculty member and feedback is provided to the student electronically. The student also reflects upon their OCP as well. With the increase in student cohort size needed to meet present and future workforce demands and limitations in faculty size, this technique helps to alleviate the logistical and operational challenges typically encountered. Additionally, this allows for a higher level of learning via reflective practice on the part of the student.

The use of simulation, multi-media clinical case simulation software and associated technology can help bridge gaps in preparing students to master vital psychomotor skills as well as communication skills and critical thinking. Additionally, these techniques can help address competencies and standards unique to healthcare professional education. The combination of simulation and video recording could also be utilized to address requirements related to interprofessional education and continual professional assessment which are now embedded in many healthcare professional program curricula.

\section{The Role of Technology in Supporting Interprofessional Team Functions}

Based on a definition offered by the World Health Organization (WHO), "interprofessional education occurs when students from two or more professions learn about, from, and with each other to enable effective collaboration and improve health outcomes" (World Health Organization, 2010, p. 7). As healthcare delivery continues to evolve around the notion of a team of care providers working together to improve patient outcomes, interprofessional education (IPE) becomes a critical component of success. 
Regardless of primary discipline, educators' focus should be on providing students interprofessional experiences that can transform the way they learn and practice with members from other disciplines.

A recent report published by the Interprofessional Education Collaborative Expert Panel recommended that critical core competencies for IPE should be: process oriented; integrated across the learning continuum; and outcome driven (Interprofessional Education Collaborative, 2011, p.2). Similarly, the Macy Foundation has emphasized the urgent need to "accelerate the design, implementation, and evaluation of innovative models linking interprofessional education and collaborative practice” ( 2013, p. 2). Both perspectives reinforce the potential role technology can play as a catalyst and enabler of integration across professional boundaries to help improve collaboration and quality of care among healthcare professionals.

As an illustration of this potential, a recent meta-review of the literature on interprofessional education, spanning 83 studies and involving over 20,000 students across 15 countries, revealed that $27 \%$ of the educational interventions examined in these studies involved simulation and $16 \%$ involved elearning (Abu-Rish et al., 2012). Furthermore, lack of technology support was perceived as a critical barrier in only $2 \%$ of the educational interventions, suggesting that-if and when there were barriers to implementation - the issues were mainly related to human and process factors. For that reason, coupled with the ease of access to technology in academic and clinical settings, the integration of technology in educational interventions is becoming essential.

Hence, online discussion boards, wiki modules, and survey tools are being utilized more extensively to advance interprofessional education-either as stand-alone interventions or as complementary components to traditional classroom delivery (Abu-Rish et al., 2012; Smith, Antony, Koeuth, Collins, \& Frisby, 2013). Thomas Jefferson University’s Interprofessional Education Center (JCIPE) offers a two-year interprofessional education curriculum through its Health Mentor Program, where nursing, medical, pharmacy, occupational therapy, physical therapy, and couples and family therapy students participate in discussion boards to reflect on their experiences with their health mentors (a person who may have several chronic illnesses) as they work in teams to develop treatment plans (Collins et al., 2013). The same students also use a wiki platform to collectively construct their team experience and "build upon and organize concepts essential to understanding the core competencies of interprofessional education" (Smith et al., 2013, p. 1). In this program, the quality of students' interactions is assessed using an online survey grounded in the Team Performance Scale (Thompson et al., 2009), where mean team scores pertaining to collaborative learning, group processing, and collective performance are automatically calculated and distributed to students (Smith et al., 2013).

Clinical case simulations involving the aforementioned standardized patient encounters or high fidelity simulators are also perceived as highly effective methods for delivering interprofessional education to teams of healthcare students (Howell, 2009; Sandmire \& Boyce, 2004). At GW, medical, nursing, physician assistant, and physical therapy students interacted as a team after attending a series of clinical case simulations involving standardized patients. As a result, participating students reported that they were interested in seeking more opportunities to work in teams with other health professionals, as this format allowed them to more effectively learn the process of team development, conflict resolution and team leadership (Ekmekci et al., 2013). Students attending the educational intervention had significantly higher scores, as measured by the Team Assessment Inventory (Elledge \& Phillips, 1994) in the domains of productivity, roles, processes, relationships, and leadership. The results of this educational intervention suggests that "integrating interprofessional team simulations and executive coaching, as part of core healthcare curriculum, may be an effective way to enhance team-based healthcare delivery, leadership capacity, and professional development at the individual and team levels” (Elledge \& Phillips, p. 23).

Advances in telehealth have blurred the fine line between education and practice, allowing educators and practitioners to get together in virtual environments to create rich learning experiences for students. The T-Health Amphitheater run by the University of Arizona is an example of how social networking platforms were utilized to connect patients, clinicians, faculty members, and students across the state (Weinstein et al., 2010). In this configuration, a specialized video conferencing hub allows 
medical, nursing, pharmacy, and public health students to engage in conversations and in-depth exchanges with clinicians delivering healthcare to patients over a telehealth platform. Site studies have not only shown that interprofessional teams were highly effective in providing care to patients using telemedicine technologies, but that students participating in telehealth exchanges increased their knowledge and socialization (Weinstein et al.).

\section{Use of Informatics, Electronic Medical Records and Dashboards}

Informatics, the science and art that turns data into information (Hebda \& Czar, 2013) is becoming increasingly important as we strive to improve healthcare quality, performance and efficiency. The Institute of Medicine’s (IOM) report “Health Professions Education: A Bridge to Quality” (Long, 2003), noted the following overarching vision for programs engaged in educational preparation of healthcare professionals: "All health professionals should be educated to deliver patient-centered care as members of an interdisciplinary team, emphasizing evidence-based practice, quality improvement approaches, and informatics” (p.45). Presently, some healthcare profession educational programs include informatics in their curricula. Physician assistant and medical residency training programs cite graduate level competencies in order to manage and access patient data and facilitate learning (Accreditation Council for Graduate Medical Education, 2013; NCCPA, ARC-PA, AAPA, \& PAEA, 2012). However the nursing profession has led the way regarding competencies in the area of informatics. As early as 2003 nursing identified informatics as a needed competency for the advanced practitioner (Curran, 2003) and the American Association of Colleges of Nursing (2006) noted that information systems/technology and patient care technology for the improvement and transformation of healthcare was an essential competency for Doctor of Nursing. Although identified as an essential, Dolansky and Moore (2013) noted that informatics competencies were most typically actualized at the individual level and not at the systems level where quality improvement projects and safety initiatives could be implemented.

Informatics has not yet been identified as an essential competency for other programs, such as Doctor of Physical Therapy programs as advocated by Wilkinson et al., (2010) and Lobach (2004). Lobach noted that skills of knowledge management such as using research evidence and clinical practice guidelines are an application of informatics in a clinical practice setting. Physical therapist students surveyed by Meyer and Willett (2007) regarding IOM competencies noted although core competencies of quality improvement and informatics were addressed in the educational curricula, that documentation and billing made up sixty percent of the content in the informatics category. Following a review of institutional websites, informatics content was only noted in three of the currently accredited physical therapy educational programs (Central Michigan University Physical Therapy; Drexel University Doctor of Health Science in Rehabilitation Science; Emory University Doctor of Physical Therapy). More recently, GW's Doctor of Physical Therapy program introduced informatics into the curriculum framed within the context of the Triple Aim of Healthcare Reform. The students were asked to consider the concept of systems skills including how data could be used to affect clinical practice and subsequent identification of problems and systems solutions. Ultimately, students appreciated that data input into an electronic medical record (EMR) and billing system could ultimately be used to improve quality and efficiencies in care. Clearly this content area requires further exploration within the context of a health education program in order to align with IOM competencies and meet societal needs.

To prepare students to be leaders, innovators, and competent clinicians, they need to have an understanding of the increasingly salient role of informatics and specifically the use of graphical display such as dashboards. A dashboard is a visual tool that provides at a glance some of the pre-identified key performance indicators necessary to inform decisions or processes (Alexander \& Walkenbach, 2010). Clinical dashboards are designed to organize and provide easily accessible summary information on specific patient or clinical performance measures that assist in clinical decision-making. For example, development of a diabetes dashboard improved the efficiency and accuracy of acquiring data needed for high-quality diabetes care by primary care physicians in an ambulatory care setting. Additionally, quality dashboards were developed by a University Hospital Department of Neurosurgery to help manage 
processes and outcomes measures leading to improvement and change (McLaughlin, Afsar-Manesh, Ragland, Buxey, \& Martin, 2014). Dashboards are increasingly used by healthcare systems and clinics to improve efficiencies and performance by monitoring individual clinician performance, patient status and progress, safety, customer service, financial performance, market penetration, referral sources and readmissions. On regional or national levels, dashboards can provide information to inform policy development, regulations or legislation.

\section{Filling the Gaps}

One example of critical systems thinking in informatics is the development and updating of EMRs. Federal efforts driven by the Health Information Technology for Economic and Clinical Health (HITECH) Act, 2009 are underway to transform healthcare by increasing the use of EMRs (Blumenthal, 2010). Widespread adoption of EMRs in the U.S. Healthcare System is expected to reduce cost, improve healthcare quality, patient safety and outcomes (Buntin, Burke, Hoaglin, \& Blumenthal, 2011; Chaudhry et al., 2006). However, despite the potential benefits of EMRs, healthcare providers have been slow to incorporate this technology into clinical practice (Buntin et al., 2011; Ludwick \& Doucette, 2009). Lack of technological skills among clinicians is often cited as a barrier to its use (Boonstra \& Broekhuis, 2010; Bredfeldt, Awad, Joseph, \& Snyder, 2013). Additionally, few health professional programs provide didactic training on EMRs in the curriculum (Borycki, Griffith, Reid, Kushniruk, \& Kuo, 2013; Flood, Gasiewicz, \& Delpier, 2010), which further perpetuates the “competency gap”. EMRs are expected to be integral to the provision of patient care and deliberate teaching of this technology within the health professional curricula which will better prepare future graduates to effectively use these systems.

A fully operable EMR can be used to create and store a legal medical record, facilitate communication, assist with medication and test results management as well as track and monitor patient data and facilitate clinical decision making (Buntin et al., 2011). Educational training programs struggle with efforts to incorporate use of operable EMRs in their curricula (Milano, Hardman, Plesiu, Rdesinski, \& Biagioli, 2014; Wald, George, Reis, \& Taylor, 2014). Student documentation in an actual patient EMR raises concerns related to patient safety, liability and accurate billing and reimbursement (Mintz, Narvarte, O’Brien, Papp, Thomas, \& Durining, 2009). As an alternative, an academic EMR (AEMR), which has similar functionality as the EMR (Johnson \& Bushey, 2011) can be used as a tool in the educational setting to introduce students to this technology while also fostering student development of core professional competencies (Barnett, 2013; Wald et al., 2014). Health informatics (Borycki et al., 2013), effective communication (Bowers et al., 2011; Morrow et al., 2009) clinical documentation (Stephens, Gimbel, \& Pangaro, 2011) and disease prevention and management (Milano et al., 2014) can all be addressed with an AEMR, however barriers exist with implementation of an AEMR as well. Faculty familiarity with the systems, lack of institutional personnel trained to implement and manage this technology, cost, and EMR vendors with different training requirements (Borycki et al., 2013) make adoption of this technology challenging.

\section{Enhancing Communication through Social Media}

With the advent of Web 2.0, users are no longer passive participants but can actively create and contribute to content web-based services and applications such as blogs, wikis, and social networks (Anderson, 2007). Within health professional education, these virtual spaces naturally lend themselves as active learning tools in the classroom and within a professional curriculum. An exploratory study by Mi and Gould (2014) described how a small group wiki project was integrated into a neuroscience course for first year medical students in order to enhance clinical reasoning skills, reinforce literacy skills, and enhance understanding of the primary content of the course. This assignment proved to be challenging in that it required group work and assessment outside of the typical multiple-choice testing format. It allowed students the ability to synthesize information and deploy it clinically through a user-friendly, web-based wiki platform (Mi \& Gould). Student surveys showed mixed results with positive student 
feedback regarding comfort level and use of the tool, however usefulness of a wiki to facilitate group learning and its effectiveness as an online learning tool were of questionable value.

In 2013, GW physical therapy students used Twitter $^{\circledR}$, a micro-blog, to engage in active, virtual conversations to reflect on their clinical internship experiences. The objectives of the assignment were to increase student proficiency in professional use of social media and to develop concise but reflective original posts and comments to peers. Students completed a survey following the assignment which revealed a positive response in its ability to meet the learning objectives. Comments specifically supported an appreciation for practicing professional communication skills while using a social media platform. Additionally, multiple students commented they were interested in continuing live tweet sessions during their upcoming clinical internship experiences. Students responded that tweeting gave them an opportunity to see the similarities between individual experiences and found the experience "supportive."

Social media is prevalent in both personal and professional contexts. As future healthcare professionals, students enrolled in health professional programs must be able to view the use of social media through a new lens as well as garner an appreciation for how future patients, consumers, and colleagues employ its use. In 2009, Chertien and colleagues surveyed U.S. medical schools on incidence of unprofessional postings on social media by medical students. Sixty percent of the schools responded and of the respondents, $60 \%$ of the schools (Milano et al., 2014) reported unprofessional postings. This included violations of patient privacy, evidence of intoxication or substance abuse, profanity, discriminatory language and sexually suggestive content. The authors also found that policies and procedures related to professional behavior typically did not explicitly describe expectations related to blogs and social networking sites.

Many students entering healthcare fields are avid users of social media sites (Giordano \& Giordano, 2011). In order to connect with students, it would be beneficial for educators to use these tools. In addition and perhaps more importantly, educators have an obligation as well to guide students in appropriate professional use. Under faculty supervision, students can harness the strengths that social media has to offer and with feedback employ its use professionally in a low stakes context. Ultimately the goal is for communication, in whatever format, to reflect positively upon students, the institution of higher learning and ultimately the profession. Research on the pedagogical use of social media in health professional programs is in its early stages. Further exploration of its ability to facilitate communication or act as a medium for reflection is needed if it is to become an accepted professional means of communicating.

\section{Promoting Information Literacy}

The medical or health sciences library at any university that trains healthcare professionals is a vital partner in preparing students to provide high quality care based on published research. Best practices in healthcare depend on accessing and synthesizing a vast body of health-related literature, and applying the results to the care of patients. Traditional librarianship has often followed a mostly reactive model in which patrons identify a need and then seek support from their library. However, technology has facilitated the development of a more active approach to this process.

Information literacy has been an important concept for framing and guiding these advancements. Broadly speaking, information literacy is "the set of skills needed to find, retrieve, analyze, and use information” (Association of College and Resource Libraries, 2014). The acquisition of information literacy skills prepares students to be lifelong learners able to sift through a haze of information to efficiently identify, locate, analyze, and use high-quality information sources. One essential component of healthcare professional education is the emphasis on evidence-based practice. Evidence-based practice is integration of the best available evidence to inform patient care (Green \& Corcoran, 2011). This concept is strongly related to information literacy and together they form the basis of much of the instruction that health sciences librarians provide as well as an underlying set of principles which guide the increasing use of technology within health sciences librarianship. 
To help health science librarians step away from the traditional reactive model of support, there have been numerous online tools developed to better provide patrons with 'just in time' information. One such tool is LibGuides - a content management platform created by SpringShare. LibGuides allow librarians to create a repository of curated links developed specifically to guide a certain sub-population of patrons (defined by department, major, topic of interest, etc.). LibGuides supports patrons' needs at times when librarians are not available to give direct assistance. One example of the use of LibGuides in a health sciences environment is the creation of LibGuides that match the architecture of a medical curriculum to supply students with targeted resources based on their current topic of study (Neves \& Dooley, 2011).

Another recent innovation in health sciences librarianship facilitated by the use of technology is the online 'embedded librarian' model. This refers to the placement of a health sciences librarian within an online component of a course via course management software. Activities of the embedded librarian may include training students to evaluate and retrieve appropriate information resources, providing guidance with bibliographic management products, giving a point of contact within the library, and more. There is some evidence this service is useful for helping students feel more confident in their abilities to appraise research articles, search common article databases, conduct literature reviews, as well as other related information literacy and evidence-based practice skills (Kumar, Wu, \& Reynolds, 2014). At the GW Himmelfarb Health Sciences Library, the practice of embedding librarians in courses has grown rapidly in recent years. During the 2013-2014 school year alone librarians were embedded in over 60 different sections of online classes.

Additionally, and often in connection with the 'embedded librarian' model, is the provision of live, online instructional sessions (Konieczny, 2010). Even in an asynchronous class environment, synchronous sessions can be provided using web-conferencing programs such as Adobe ${ }^{\circledR}$ Connect or Blackboard Collaborate. Additionally, these sessions can be recorded and made available for the benefit of those students unable to attend the live session.

\section{Filling the Gaps}

As noted earlier, health sciences librarians have become a more active participant in online learning environments. However, there is still room for growth. Given the variety of work and educational backgrounds of online students, more effort should be made to identify the specific needs of this heterogeneous group so that librarian-led instructional interventions will best address areas of actual knowledge deficiencies to support students' development of information literacy and evidence-based practice skills. Additionally, librarians can help online students feel a greater connection to their university by not only providing well-tailored educational support, but by also being available to help students in ways that mesh with individual students' unique needs and situations.

The 'flipped classroom' model may also help inform future directions in librarian's support of online learning. The 'flipped classroom' refers to students engaging in self-paced activities before scheduled class time which is reserved for more focused activities and interventions (Educause Learning Initiative, 2012). By embracing this model for library informatics offerings, librarians can make sure they are respecting the time of students who have many competing obligations. By creating pre-work exercises that can be completed at a convenient time and pace for the students, and which report results back to the health sciences librarian, educational sessions can be optimized to meet student needs.

Technological solutions exist that can help librarians build their interventions to better reflect the 'flipped classroom' model. Camtasia is one such tool that has been used in support of health sciences education (Schroeder, 2010). Camtasia is a screen capture program that allows users to create narrated tutorials with embedded quizzes and other interactive content. Camtasia quizzes report results back to the tutorial creators and can therefore be used to identify existing strengths and weaknesses in the student's subject knowledge. The benefit of using Camtasia, as opposed to simply sending students a pre-test, is that the tutorials allow you to share some remedial instruction to ensure that everyone has a basic conception of some aspects of a topic given the heterogeneous nature of online students' experiences. 
Through the use of such tools, health sciences librarians can build on past successes and support the development of information literacy skills among the students they serve. Through the development of these skills, students will be equipped to effectively promote and engage in evidence-based healthcare delivery in their professional careers.

\section{Online Learning and Management Systems}

Online content delivery is no longer a foreign concept in healthcare professional education and the use of a learning management system (LMS) has become a mainstay of course organization programs. Commonly used platforms include commercial-based products (e.g., Blackboard, Desire2Learn) as well as open source versions (e.g., Moodle, Sakai, OLAT) most of which operate via a cloud-based system known as Software as a Service (SaaS). Content delivery can be easily accomplished with these systems in a traditional format (e.g., syllabus and handout repository, online narrated lectures, and discussion boards) though most are beginning to incorporate Web 2.0 strategies such as wikis, video conferencing, and other online collaborative technologies (Ellaway \& Masters, 2008; Hanss, Jemison, \& Alrbight, 2008). Though posting reading assignments and narrated PowerPoint slides to a module in an LMS may still be considered "online learning," this passive learning strategy does not fully incorporate the potential of online content delivery nor does it fully enhance the learning experience. Use of interactive online content delivery platforms (e.g., Adobe Captivate, Blackboard Collaborate, Articulate Storyline) do however, create the possibility of more fully engaging the learner with online content. In the setting of health professional education, when content is delivered online, attempts to make such delivery interactive will result in enhanced learning and retention (Kerfoot, Conlin, \& McMahon, 2006). Even in the absence of enhanced learning there is still a greater perceived benefit of interactive online content delivery compared to passive online learning by the learners themselves (Kerfoot et al.)

There are some significant drawbacks to the use of online content delivery systems that should be addressed prior to fully embracing this technology. The first potential drawback is the technology itself including the quality and availability of an LMS, websites that host content, and the reliability of each. A second drawback is the willingness of the teacher and learner to accept the technology, become trained on its use, and know what to do when the system fails them individually or collectively. And finally, building an online course is labor-intensive; in fact, some may argue that it takes significantly more time and effort to create a high quality online course than a traditional classroom based course.

Attempts to bridge the gaps between the available technology and its users do exist. Training modules or tutorials for virtually every LMS and online collaborative technology are already available. This may help users become familiar with the technology, but it does not guarantee quality content. The Association of Program Directors in Internal Medicine (APDIM) attempted to tackle the issue of gauging quality of e-learning tools for internal medicine residents (Myers et al., 2012). The end product of their efforts is a resource list of openly available e-learning websites on a variety of medical topics (e.g., cardiac auscultation, reading chest x-rays, etc.), each of which has been "graded" using a scoring system established by the E-Learning Task Force of the APDIM. Though this resource list is not all encompassing of every healthcare education topic, it does help create a framework for building evaluative systems of existing online content for the purposes of delivering said content to healthcare professional students.

Finally, the use of Massive Open Online Courses (MOOCs) may help address the seemingly burdensome task of building an online course. A MOOC is an open source online course that is, in general, hosted by an established leader in higher education and online learning. Examples in healthcare education include several offerings by the University of California, San Francisco, and edX-a consortium of online educators from dozens of institutions of higher education including Harvard, MIT, Berkley and The University of Texas. A MOOC may have thousands of students enrolled in a course at one time, making it possible to educate the masses in a single, online venue. Though MOOCs are not currently being used to replace coursework within health professional education, it is possible that these open online courses may be used in conjunction with the curriculum or supplement pre-requisite 
requirements (Harder, 2013). Thus, a teacher or educational program does not have to reinvent the wheel when developing an online healthcare education course if similar content has already been made available via an established MOOC at another institution.

\section{Summary}

Healthcare professional education must be responsive to a wide range of factors. Legislative changes implemented to enhance the efficiency or quality of healthcare must be immediately integrated into curricula so that students will be prepared to practice in the healthcare environment in existence at graduation. Technological innovations, such as EMRs and dashboards, must be introduced in the classroom so that students fully understand and appreciate how new technologies can be ethically and effectively applied to everyday practice. Innovations in healthcare, such as evidence-based practice and interprofessional care, must also be taught and reinforced throughout the curriculum to ensure translation to practice. Finally, professional accreditation standards require students meet a certain level of competency in knowledge, clinical reasoning, critical thinking, and psychomotor skills. Increasingly, healthcare education has addressed these factors by enhancing teaching and learning through technology. This article has summarized the literature and discussed how one university (The George Washington University, Washington DC) uses technology to prepare future health professionals to work in a complex healthcare environment.

\section{References}

Abu-Rish, E., Kim, S., Choe, L., Varpio, L., Malik, E., White, A.A \& Zierler, B. (2012). Current trends in interprofessional education of health sciences students: A literature review. Journal of Interprofessional Care, 26(6), 444-451. doi:10.3109/13561820.2012.715604 [doi]

Accreditation Council for Graduate Medical Education. (2013). ACGME Common program requirements. Retrieved from

https://www.acgme.org/acgmeweb/Portals/0/PFAssets/ProgramRequirements/CPRs2013.pdf

Alexander, M., Walkenback, J. (2010). Excel dashboards and reports. (2010). Hoboken, NJ. John Wiley \& Sons, Inc.

American Association of Colleges of Nursing. (2006). DNP Roadmap Task Force Report. Retrieved from http://www.aacn.nche.edu/dnp/roadmapreport.pdf.

Anderson, P. (2007). What is web 2.0? ideas, technologies and implications for education. JISC

Technology and Standards Watch. Retrieved from

http://www.jisc.ac.uk/media/documents/techwatch/tsw0701b.pdf

Association of College and Resource Libraries. (2014). Introduction to information literacy. Retrieved from http://www.ala.org/acrl/issues/infolit/overview/intro

Barnett, J. S. (2013). Incorporating electronic medical records into the physician assistant educational curriculum. The Journal of Physician Assistant Education. 24(2), 48-54.

Bembridge, E., Levett-Jones, T., \& Jeong, S. Y. (2011). The transferability of information and communication technology skills from university to the workplace: a qualitative descriptive study. Nurse Education Today, 31(3), 245-252. doi:10.1016/j.nedt.2010.10.020 [doi]

Blumenthal, D. (2010). Launching HITECH. The New England Journal of Medicine, 362(5), 382-385. doi:10.1056/NEJMp0912825 [doi] 
Boonstra, A., \& Broekhuis, M. (2010). Barriers to the acceptance of electronic medical records by physicians from systematic review to taxonomy and interventions. BMC Health Services Research, 10, 231-6963-10-231. doi:10.1186/1472-6963-10-231 [doi]

Borycki, E. M., Griffith, J., Reid, P., Kushniruk, A. W., \& Kuo, M. (2013). Do electronic health records help undergraduate health informatics students to develop health informatics competencies? studies in health technology and informatics. Studies in Health Technology and Informatics, 192, 1106.

Bowers, A. M., Kavanagh, J., Gregorich, T., Shumway, J., Campbell, Y., \& Stafford, S. (2011). Student nurses and the electronic medical record: a partnership of academia and healthcare. Computers, Informatics, Nursing : CIN, 29(12), 692-697. doi:10.1097/NCN.0b013e31822b8a8f [doi]

Bredfeldt, C. E., Awad, E. B., Joseph, K., \& Snyder, M. H. (2013). Training providers: beyond the basics of electronic health records. BMC Health Services Research, 13, 503. doi:10.1186/1472-6963-13503 [doi]

Bulik, R. J., \& Shokar, G. S. (2010). Integrating telemedicine instruction into the curriculum: Expanding student perspectives of the scope of clinical practice. Journal of Telemedicine and Telecare, 16(7), 355-358. doi:10.1258/jtt.2010.090910 [doi]

Buntin, M. B., Burke, M. F., Hoaglin, M. C., \& Blumenthal, D. (2011). The benefits of health information technology: a review of the recent literature shows predominantly positive results. Health Affairs (Project Hope), 30(3), 464-471. doi:10.1377/hlthaff.2011.0178 [doi]

Center for Integration of Medicine and Innovative Technology (CIMIT). (2014). Accelerating the healthcare innovation cycle by facilitating collaboration among experts through the development and implementation of novel solution to improve patient care. Retrieved fromhttp://www.cimit.org/

Central Michigan University Physical Therapy. Retrieved from https://www.cmich.edu/colleges/CHP/hp academics/physical therapy/Pages/Doctoral-Program-inPhysical-Therapy.aspx

Chaudhry, B., Wang, J., Wu, S., Maglione, M., Mojica, W., Roth, E., Shekelle, P. G. (2006). Systematic review: impact of health information technology on quality, efficiency, and costs of medical care. Annals of Internal Medicine, 144(10), 742-752. doi:0000605-200605160-00125 [pii]

Chretien, K. C., Greysen, S. R., Chretien, J. P., \& Kind, T. (2009). Online posting of unprofessional content by medical students. The Journal of the American Medical Association, 302(12), 1309-1315. doi:10.1001/jama.2009.1387 [doi]

Collins, L., Ankam, N., Antony, R., Hewston, L., Koeuth, S., Smith, K., Arenson, C. (2013). Preparing students for collaborative practice: an overview of the 2012 Jefferson health mentors program. Retrieved from https://www.mededportal.org/publication/9312

Creedon, S. A., \& Cummins, A. M. (2012). Development of a blended model of teaching and learning for nursing students on rostered placement to ensure competence in information and communication technology for professional practice in Ireland. Computers, Informatics, Nursing, 30(5), 274-279. doi:10.1097/NCN.0b013e31823eb652 [doi]

Curran, C. R. (2003). Informatics competencies for nurse practitioners. American Association of Critical Care Nurses Clinical Issues, 14(3), 320-330.

Dolansky, M. A., \& Moore, S. M. (2013). Quality and safety education for nurses (QSEN): The key is systems thinking. OJIN: The Online Journal of Issues in Nursing, 18(3) doi:10.3912/OJIN.Vol18No03Man01

Drexel University Doctor of Health Science in Rehabilitation Science., Retrieved from http:// www.drexel.edu/physicalTherapy/programs/dhscRehabilitation/ 
Educause Learning Initiative. (2012). Seven things you should know about flipped classrooms. Retrieved from http://net.educause.edu/ir/library/pdf/ELI7081.pdf

Ekmekci, O., Plack, M., Pintz, C., Bocchino, J., LeLacheur, S., \& Halvaksz, J. (2013). Integrating executive coaching and simulation to promote interprofessional education of health care students. Journal of Allied Health, 42(1), 17-24.

Ellaway, R., \& Masters, K. (2008). AMEE guide 32: E-learning in medical education part 1: Learning, teaching and assessment. Medical Teacher, 30(5), 455-473. doi:10.1080/01421590802108331 [doi]

Elledge, R., \& Phillips, S. (1994). Team building for the future: Beyond the basics. San Diego, CA: Pfeiffer \& Company.

Emory University Doctor of Physical Therapy. Retrieved from http://www.rehabmed.emory.edu/xvpt/programs/.

Floor, L.S., Gasiewicz, N., \& Delpier, T. (2010). Integrating information literacy across a BSN curriculum. Journal of Nursing Education, 49(2), 101-104.

Gastmyer, C. L., \& Pruitt, B. E. (2014). The impact of the affordable care act on health education: Perceptions of leading health educators. Health Promotion Practice, 15(3), 349-355. doi:10.1177/1524839913499348 [doi]

Giordano, C., \& Giordano, C. (2011). Health professions students' use of social media. Journal of Allied Health, 40(2), 78-81.

Green, R., \& Corcoran, M. (2011). Evidence-based practice, information literacy, and graduate inquiry: a collaborative learning and teaching experience. 39th Annual LOEX (Information Literacy Exchange) Conference, Ft. Worth, TX. 39th, Ft. Worth, TX.

Hanss, T., Jemison, J. \& Alrbight, S. (2008). A learner-centered infrastructure: The next generation learning management system. Retrieved from www.aamc.org/members/gir/gir resources/112070/viewpoint nov08.html

Harder, B. (2013). Are MOOCs the future of medical education? British Medical Journal, 346. 2666. doi:10.1136/bmj.f2666

Hawkins, S. Y. (2012). Telehealth nurse practitioner student clinical experiences: An essential educational component for today's health care setting. Nurse Education Today, 32(8), 842-845. doi:10.1016/j.nedt.2012.03.008 [doi]

Hebda, T., \& Czar, P. (2013). Handbook of informatics for nurses and healthcare professionals. (6th ed.). Boston, MA: Pearson Education, Inc.

Henry, S.G., Holmboe, E.S., Frankle, F.M. (2013). Evidence-based competencies for improving communication skills in graduate medical education: a review with suggestions for implementation. Medical Teacher, 35, 395-403.

Higgs, J., \& Jones, M. A. (2000). Clinical decision making and multiple problem spaces. Clinical reasoning in the health professions (2nd ed., pp. 3-14). Oxford: Butterworth-Heinemann.

Howell, D. (2009). Occupational therapy students in the process of interprofessional collaborative learning: A grounded theory study. Journal of Interprofessional Care, 23(1), 67-80. doi:10.1080/13561820802413281 [doi]

Intel Corporation. (2010). Information and communication technology (ICT) is transforming healthcare education in the Philippines. Retrieved from http://www.who.int/pmnch/events/partners_forum/ICT_transforming_Healthcare_Education_Philipp ines.pdf 
Interprofessional Education Collaborative. (2011). Core competencies for interprofessional collaborative practice. Washington, DC.

Jerant, A. F., \& Azari, R. (2004). Validity of scores generated by a web-based multimedia simulated patient case software: A pilot study. Academic Medicine, 79(8), 805-811. doi:79/8/805 [pii]

Johnson, D. M., \& Bushey, T. I. (2011). Integrating the academic electronic health record into nursing curriculum: preparing student nurses for practice. Computers, Informatics, Nursing. 29(3), 133-137. doi:10.1097/NCN.0b013e3182121ed8 [doi]

Kerfoot, B. P., Conlin, P. R., \& McMahon, G. T. (2006). Comparison of delivery modes for online medical education. Medical Education, 40(11), 1137-1138. doi:MED2588 [pii]

Konieczny, A. (2010). Experiences as an embedded librarian in online courses. Medical Reference Services Quarterly, 29(1), 47-57. doi:10.1080/02763860903485084 [doi]

Kumar, S., Wu, L., \& Reynolds, R. (2014). Embedded librarian within an online health informatics graduate research course: A case study. Medical Reference Services Quarterly, 33(1), 51-59. doi:10.1080/02763869.2014.866485 [doi]

Lam, M. K., Amon, K. L., Nguyen, M., Campbell, A. J., \& Neville, V. (2012). The effect of e-health contents on health science students' attitude toward the efficiency of health ICT in care provision. Studies in Health Technology and Informatics, 178, 99-104.

Levett-Jones, T., Kenny, R., Van der Riet, P., Hazelton, M., Kable, A., Bourgeois, S., \& Luxford, Y. (2009). Exploring the information and communication technology competence and confidence of nursing students and their perception of its relevance to clinical practice. Nurse Education Today, 29(6), 612-616. doi:10.1016/j.nedt.2009.01.007 [doi]

Lobach, D. (2004). Clinical informatics: Supporting the use of evidence in practice and relevance to physical therapy. Journal of Physical Therapy Education, 18(3), 24-34.

Long, K. (2003). The institute of medicine report health professions education: a bridge to quality. Policy Politics Nursing Practice, 4(259) doi:10.1177/1527154403258304

Ludwick, D. A., \& Doucette, J. (2009). Primary care physicians' experience with electronic medical records: Barriers to implementation in a fee-for-service environment. International Journal of Telemedicine and Applications, 2009, 853524. doi:10.1155/2009/853524 [doi]

Macy Foundation. (2013). Transforming patient care: Aligning interprofessional education with clinical practice redesign. Conference Proceedings. Retrieved from http://macyfoundation.org/docs/macy_pubs/TransformingPatientCare_ConferenceRec.pdf;

Maldonado, R. (2011). The use of multimedia clinical case scenario software in a problem-based learning course: impact on faculty workload and student learning outcomes. Journal of Physician Assistant

Education, 22(3), 51-55. Retrieved from http://search.ebscohost.com/login.aspx?direct=true\&db=rzh\&AN=2011334058\&site=edslive\&scope=site\&authtype=ip, uid\&custid=s8987071

Mason, P. B., Turgeon, B. M., Cossman, J. S., \& Lay, D. M. (2014). The use of technology and perceptions of its effectiveness in training physicians. Medical Teacher, 36(4), 333-339. doi:10.3109/0142159X.2014.887837 [doi]

McLaughlin, N., Afsar-Manesh, N., Ragland, V., Buxey, F., \& Martin, N. (2014). Tracking and sustaining improvement initiatives: leveraging quality dashboards to lead change in a neurosurgical department. Neurosurgery, 74(3), 235-243. 
Meyer, K. P., \& Willett, G. (2007). Are physical therapy clinical instructors teaching the institute of medicine core competencies? an exploratory investigation using student perceptions. Journal of Allied Health, 36(4), e293-312.

Mi, M., \& Gould, D. (2014). Wiki technology enhanced group project to promote active learning in a neuroscience course for first-year medical students: An exploratory study. Medical Reference Services Quarterly, 33(2), 125-135. doi:10.1080/02763869.2014.897509 [doi]

Milano, C. E., Hardman, J. A., Plesiu, A., Rdesinski, R. E., \& Biagioli, F. E. (2014). Simulated electronic health record (sim-EHR) curriculum: teaching EHR skills and use of the EHR for disease management and prevention. Academic Medicine, 89(3), 399-403. doi:10.1097/ACM.0000000000000149 [doi]

Mintz, M., Narvarte, H.J., O'Brien, K.E., Papp, K.K., Thomas, M., \& Durning, S.T. (2009). Use of electronic medical records by physicians and students in academic internal medicine settings. Academic Medicine. 84(12), 1698-1704.

Morrow, J. B., Dobbie, A. E., Jenkins, C., Long, R., Mihalic, A., \& Wagner, J. (2009). First-year medical students can demonstrate EHR-specific communication skills: a control-group study. Family Medicine, 41(1), 28-33.

Myers, J. D., Didwania, A., Shah, C., Jacobson, D., Norwood, D., Ehtesham, M., \& Aronowitz, P. (2012). E-learning-the new frontier: A report from the APDIM E-learning task force. The American Journal of Medicine, 125(12), 1234-1237. doi:10.1016/j.amjmed.2012.08.009 [doi]

NCCPA, ARC-PA, AAPA, \& PAEA. (2012). Competencies for the physician assistant profession. NCCPA, ARC-PA, AAPA, \& PAEA. Retrieved from http://www.nccpa.net/App/PDFs/Definition\%20of\%20PA\%20Competencies\%203.5\%20for\%20Pub lication.pdf

Neves, K., \& Dooley, S. J. (2011). Using LibGuides to offer library service to undergraduate medical students based on the case-oriented problem solving curriculum model. Journal of the Medical Library Association : JMLA, 99(1), 94-97. doi:10.3163/1536-5050.99.1.017 [doi]

Pilcher, J., \& Bradley, D. A. (2013). Best practices for learning with technology. Journal for Nurses in Professional Development, 29(3), 133-137. doi:10.1097/NND.0b013e318291c220 [doi]

Rochmawati, E., \& Wiechula, R. (2010). Education strategies to foster health professional students' clinical reasoning skills. Nursing \& Health Sciences, 12(2), 244-250. doi:10.1111/j.14422018.2009.00512.x

Sandars, J. (2012). Technology and the delivery of the curriculum of the future: Opportunities and challenges. Medical Teacher, 34(7), 534-538. doi:10.3109/0142159X.2012.671560 [doi]

Sandmire, D. A., \& Boyce, P. F. (2004). Pairing of opposite learning styles among allied health students: effects on collaborative performance. Journal of Allied Health, 33(2), 156-163.

Schroeder, H. (2010). Creating library tutorials for nursing students. Medical Reference Services Quarterly, 29(2), 109-120. doi:10.1080/02763861003723135 [doi]

Smith, K., Antony, R., Koeuth, S., Collins, L., \& and Frisby, A. (2013). A computer supported interprofessional education initiative: Using technology to advance interprofessionalism. MedEdPORTAL, 6/4/2014.

Stephens, M. B., Gimbel, R. W., \& Pangaro, L. (2011). Commentary: The RIME/EMR scheme: An educational approach to clinical documentation in electronic medical records. Academic Medicine : Journal of the Association of American Medical Colleges, 86(1), 11-14. doi:10.1097/ACM.0b013e3181ff7271 [doi] 
The Royal Society. (2006). Digital healthcare: The impact of information and communication technologies on health and healthcare. London, England. Retrieved from https://royalsociety.org/ /media/Royal_Society_Content/policy/publications/2006/8218.pdf;

Thompson, B. M., Levine, R. E., Kennedy, F., Naik, A. D., Foldes, C. A., Coverdale, J. H., Haidet, P. (2009). Evaluating the quality of learning-team processes in medical education: development and validation of a new measure. Academic Medicine, 84(10), S124-7. doi:10.1097/ACM.0b013e3181b38b7a [doi]

Voogt, J., Knezek, G., Cox, M., Knezek, D., \& ten Brummelhuis, A. (2013). Under which conditions does ICT have a positive effect on teaching and learning? a call to action. Journal of Computer Assisted Learning, 29(1), 4-14. doi:10.1111/j.1365-2729.2011.00453.x

Wald, H. S., George, P., Reis, S. P., \& Taylor, J. S. (2014). Electronic health record training in undergraduate medical education: Bridging theory to practice with curricula for empowering patientand relationship-centered care in the computerized setting. Academic Medicine, 89(3), 380-386. doi:10.1097/ACM.0000000000000131 [doi]

Watson, K., Wright, A., Morris, N., McMeeken, J., Rivett, D., Blackstock, F., Jull, G. (2012). Can simulation replace part of clinical time? two parallel randomised controlled trials. Medical Education, 46(7), 657-667. doi:10.1111/j.1365-2923.2012.04295.x [doi]

Weinstein, R. S., McNeely, R. A., Holcomb, M. J., Doppalapudi, L., Sotelo, M. J., Lopez, A. M., Barker, G. P. (2010). Technologies for interprofessional education: the interprofessional educationdistributed "e-classroom-of-the-future." Journal of Allied Health, 39 Suppl 1, 238-245.

WHO (World Health Organization). (2010). Framework for action on interprofessional education and collaborative practice. Geneva, Switzerland. Retrieved from http://www.who.int/hrh/nursing_midwifery/en/

Wilkinson, S., Chevan, J., \& Vreeman, D. (2010). Establishing the centrality of health informatics in physical therapist education: if not now, when? Journal of Physical Therapy Education, 24(3), 1015. 
